\title{
Endogenous and exogenous glucocorticoids decrease plasma ghrelin in humans
}

\author{
B Otto ${ }^{1}$, M Tschöp ${ }^{2,4}$, W Heldwein ${ }^{1}$, A F H Pfeiffer ${ }^{3,5}$ and S Diederich ${ }^{3,5}$ \\ ${ }^{1}$ Medical Department, University Hospital Innenstadt, Ziemssenstrasse 1, 80336 Munich, Germany, ${ }^{2}$ Department of Pharmacology and ${ }^{3}$ Department of \\ Clinical Nutrition, German Institute of Human Nutrition, Potsdam-Rehbrücke, Germany, ${ }^{4}$ Department of Psychiatry, University of Cincinnati, \\ Cincinnati, Ohio, USA and ${ }^{5}$ Department of Endocrinology, Diabetes and Nutrition, Benjamin Franklin Medical Center, Free University Berlin, Germany \\ (Correspondence should be addressed to B Otto; Email: Baerbel.Otto@med.uni-muenchen.de)
}

\begin{abstract}
Objective: The orexigenic and adipogenic peptide hormone ghrelin is predominantly produced and secreted by the stomach and seems to transduce changes in food intake to specific neuronal circuits in the brain. The activity of ghrelin also includes stimulatory effects on the corticotropic system. However, little is known about the influence of glucocorticoids on ghrelin levels. We therefore studied human plasma ghrelin levels in the presence and absence of elevated glucocorticoid levels of either endogenous or exogenous origin.

Methods: Plasma ghrelin levels were measured in five patients with chronic hypercortisolism (aged 29-58, median 46 years) due to Cushing's syndrome before and after successful surgery for the adenoma, and in eight healthy controls (aged 24-39, median 27.5 years) before and after $30 \mathrm{mg}$ prednisolone (for 5 days) once a day in the morning (median body mass index (BMI) $22.7 \mathrm{~kg} / \mathrm{m}^{2}$ ). Plasma ghrelin levels were measured with a commercially available radioimmunoassay.

Results: In patients with Cushing's syndrome, plasma ghrelin levels were low (median $363.2 \mathrm{pg} / \mathrm{ml}$, range $161.9-525.7 \mathrm{pg} / \mathrm{ml})$ and significantly increased by $26.6 \%(P=0.04)$ after successful surgery, while BMI decreased (median $\left.26.2-24.0 \mathrm{~kg} / \mathrm{m}^{2}, P=0.04\right)$. A strong negative correlation $(r=-0.9$, $P=0.04$ ) between changes in BMI and plasma ghrelin was observed. In healthy controls, plasma ghrelin levels (median $288.7 \mathrm{pg} / \mathrm{ml}$, range $119.6-827.8 \mathrm{pg} / \mathrm{ml}$ ) were significantly suppressed by $18.3 \%(P=0.04)$ after prednisolone treatment.

Conclusions: We have shown for the first time that plasma ghrelin levels are decreased under endogenously or exogenously induced hypercortisolism, making ghrelin an unlikely candidate for causing the changes in energy balance or body composition characteristic of Cushing's disease. However, the reduced ghrelin secretion could reflect a compensation mechanism in reaction to the metabolic consequences of chronic hypercortisolism.
\end{abstract}

European Journal of Endocrinology 151 113-117

\section{Introduction}

Ghrelin, a 28 amino acid peptide, stimulates growth hormone $(\mathrm{GH})$ and adrenocorticotropin (ACTH) secretion from the pituitary as an endogenous ligand of the $\mathrm{GH}$ secretagogue receptor $(1,2)$. Ghrelin is mainly produced and secreted by the stomach and the gut (2), and a gastro-hypophyseal feedback loop seems to participate in the regulation of gastric ghrelin secretion (3). Ghrelin has been shown to promote appetite, food intake and a positive energy balance (4, 5), and might represent a mediator transducing changes in food intake to the regulatory networks in the central nervous system controlling energy homeostasis $(6-8)$.

In several recently published studies, insulin reduced circulating ghrelin levels (9-12), whereas two studies were unable to reproduce these effects $(13,14)$.
While most of these studies were using hyperinsulinemic-euglycemic clamp settings, a decrease in ghrelin levels appears to be caused mainly by a supraphysiological duration of exposure or a plasma concentration of insulin that exceeds levels observed postprandially. In obese humans, food intake (including 60\% of carbohydrates) with postprandially increased insulin response fails to suppress ghrelin levels sufficiently (15), suggesting that ghrelin may be involved in some of the multiple pathophysiological mechanisms leading to obesity and diabetes type 2 (7).

The multiple activities of ghrelin also include stimulatory effects on the corticotropic system, as systemic administration of synthetic ghrelin induces an increase in ACTH and cortisol levels in healthy subjects $(16,17)$ and shows a remarkable hyper-responsiveness of ACTH and cortisol secretion in patients with active Cushing's syndrome (17). 
Elevated glucocorticoid levels occurring in Cushing's disease as well as in therapeutic steroid administration are known to induce weight gain and hyperinsulinemia. However, little is known about the influence of glucocorticoids on endogenous plasma ghrelin levels and the regulation of ghrelin secretion under corticosteroid influences. Interestingly, gonadal steroid hormones seem to suppress circulating ghrelin in humans (18). The aim of our study was to investigate human plasma ghrelin levels in the presence and absence of endogenous and exogenous glucocorticoids.

\section{Subjects and methods}

\section{Patients}

The first group included five patients (one male and four females), aged 29-58 years (median 46 years), with chronic hypercortisolism: in three cases due to M. Cushing (ACTH-secreting microadenomas of the pituitary with no clinical signs of hypopituitarism besides cyclic abnormalities during chronic hypercortisolism) and in the two other cases due to cortisol-producing adrenal adenoma. Diagnosis was established by standardized international criteria (elevated 24-h urinary cortisol, lacking cortisol-ACTH suppression after oral dexamethasone, ACTH levels) and was confirmed after successful surgery. In these patients, morning fasting plasma ghrelin levels were measured 1 day to 7 months before surgical therapy of the adenoma. Successful treatment was confirmed by 24-h urinary cortisol. Ghrelin levels were analyzed for a second time 3-24 months after successful surgery.

\section{Controls}

The second group consisted of eight healthy male subjects, aged 24-39 years (median 27.5 years), who took $30 \mathrm{mg}$ prednisolone once a day in the morning for 5 days. Plasma ghrelin levels were measured before and after 5 days of exogenous steroid intake. Based on their clinical history, physical examination and routine laboratory findings, none of the controls enrolled in the study was affected by diabetes or other endocrine diseases, or cardiovascular, renal or liver disorders. During the study period, none of the patients or healthy subjects changed the average amount of their caloric intake, the nutrient composition of their meals or took any additional medication.

All blood samples were drawn in the morning after an overnight fast. The blood samples were immediately chilled, centrifuged, separated and frozen.

The investigation was approved by the Ethics Committee of the Medical Faculty of the Free University of Berlin, and informed written consent was obtained from each subject before entering the study.

\section{Hormone assay}

After samples were taken in ETDA tubes, blood was immediately chilled on ice and centrifuged, and aliquots were frozen at $-20^{\circ} \mathrm{C}$ until assayed. Plasma ghrelin was analyzed in all samples from individual subjects in duplicate in the same assay. Immunoreactive total human plasma ghrelin was measured by a commercially available radioimmunoassay (Phoenix Pharmaceuticals, Mountain View, CA, USA) using ${ }^{125}$ I-labeled bioactive ghrelin as a tracer and a polyclonal antibody raised in rabbits against the C-terminal end of human ghrelin. This assay recognizes both acylated and de-acylated ghrelin and the antiserum does not crossreact with any relevant peptide according to the information provided by the manufacturer. Intra- and interassay coefficients of variation were $5.3 \%$ and $13.6 \%$ respectively.

Serum insulin-like growth factor-I (IGF-I) was measured by a commercially available enzyme-labeled chemiluminescent immunometric assay (Diagnostic Products Corporation, Los Angeles, CA, USA).

\section{Statistics}

All values are given as median and range. Wilcoxon's test (patients, before and after surgery; controls, before and after prednisolone treatment) was performed for appropriate statistical comparisons. Correlations between parameters were examined using the Spearman rho correlation coefficient. $P$ values of less than 0.05 were regarded as statistically significant.

\section{Results}

\section{Patients}

Median plasma ghrelin level of patients with chronic hypercortisolism was $363.2 \mathrm{pg} / \mathrm{ml}$ (range 161$525.7 \mathrm{pg} / \mathrm{ml}$ ) and showed a significant median increase of $26.6 \%$ (median) after successful surgery of the adenoma $(n=5, P=0.04)$, as shown in Fig. 1 A.

The median body mass index (BMI) of patients before surgery was $26.2 \mathrm{~kg} / \mathrm{m}^{2}$ and was significantly lower after successful treatment $\left(24.0 \mathrm{~kg} / \mathrm{m}^{2}, P=0.04\right)$. Furthermore, a significant correlation was found between the increase in ghrelin levels and the decrease in BMI $(r=-0.9, \quad P=0.04)$. No significant correlation between plasma ghrelin levels and BMI was found.

\section{Healthy volunteers}

The median ghrelin level in healthy subjects before prednisolone therapy was $288.7 \mathrm{pg} / \mathrm{ml}$ (range $119.6-827.8 \mathrm{pg} / \mathrm{ml}$ ) and was significantly decreased by a median of $18.3 \%(n=8, P=0.04)$, as shown in Fig. 1B. The median BMI of controls was $22.7 \mathrm{~kg} / \mathrm{m}^{2}$ 


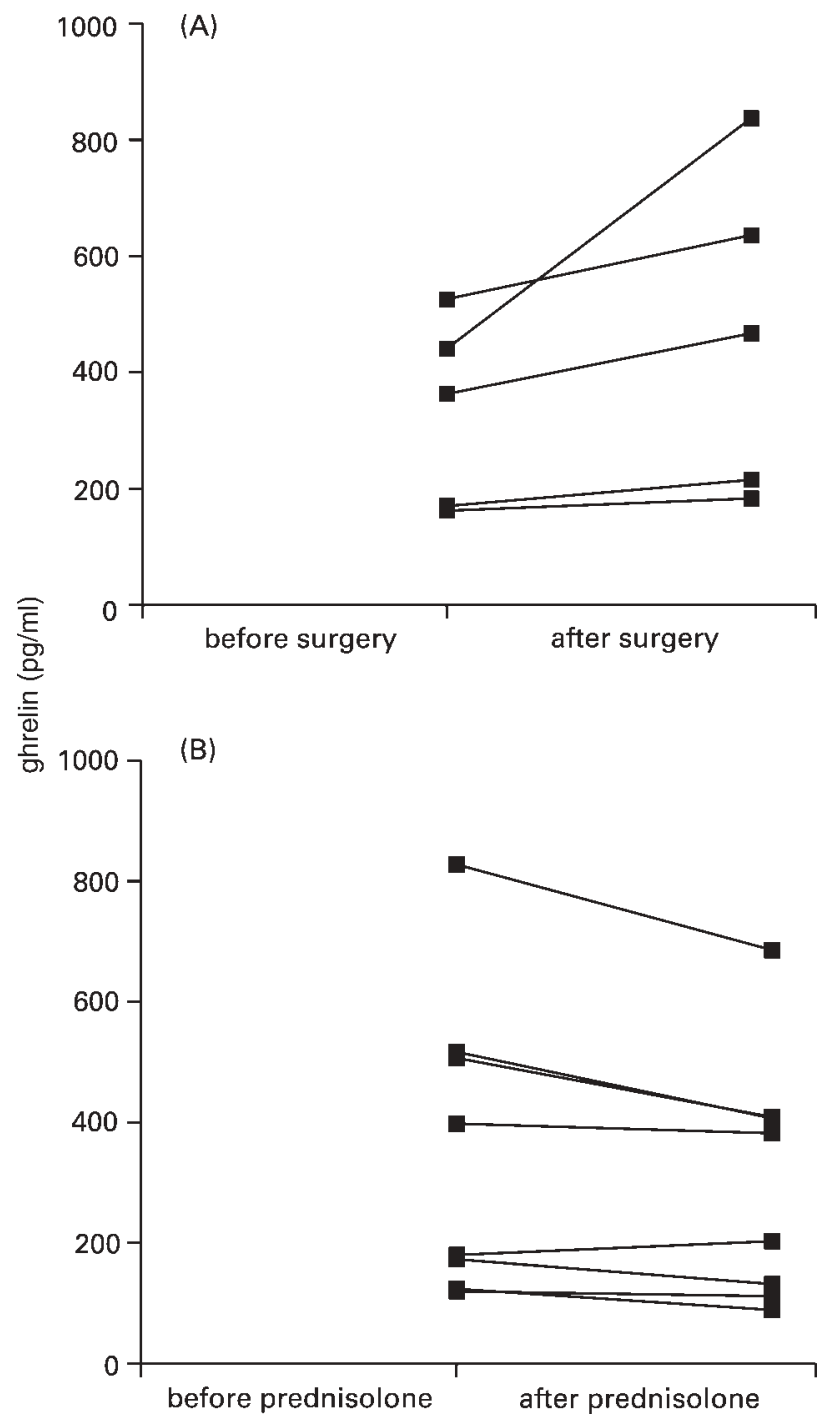

Figure 1 Plasma ghrelin levels in (A) five patients with chronic hypercortisolism before and after successful surgery for adenoma and (B) eight healthy volunteers before and after administration of $30 \mathrm{mg}$ prednisolone for 5 days.

and showed no correlation with corresponding ghrelin levels.

In healthy subjects, the initial measurement of serum IGF-I levels was $209.5 \mathrm{ng} / \mathrm{ml}$ (range $139-275 \mathrm{ng} / \mathrm{ml}$ ) and showed a median increase after prednisolone therapy of $34 \%(n=8, P=0.01)$. In addition, a significant correlation was found between the extent of the decrease in ghrelin levels and the individual increase in IGF-I $(r=-0.83, P=0.01)$. No significant correlation between ghrelin levels and BMI was found.

\section{Discussion}

The present work has shown that endogenously as well as exogenously induced hypercortisolism leads to a significant decrease in plasma ghrelin levels in humans, indicating a possible feedback mechanism between gastric ghrelin secretion and the activity levels of the hypothalamo-pituitary-adrenal (HPA) axis. It cannot be definitely ruled out whether there is a difference between ACTH-induced hypercortisolism in patients with $\mathrm{M}$. Cushing and elevated adrenal cortisol production (ACTH not detectable)-induced ghrelin decrease. But our findings (shown in Fig. 1) indicate that the decrease in ghrelin seems to be mainly mediated by changes in circulating cortisol levels.

Our findings are in accordance with earlier results on a $\mathrm{GH}$-ghrelin feedback loop between the stomach and the pituitary (3) where we investigated hypophysectomized rats and showed that hypophysectomy increases circulating plasma ghrelin levels in rats 4 weeks after surgical removal compared with plasma ghrelin levels in sham-hypophysectomized or normal rats. In GHdeficient dwarf rats $(1,2)$ plasma levels of ghrelin were not significantly different from those of normal controls (3). Therefore, the lack of pituitary hormones, but not GH deficiency alone, leads to a significant increase in circulating ghrelin levels in rodents. Our findings have shown a decrease in human ghrelin during hypercortisolism, indicating a possible feedback mechanism between the pituitary-adrenal axis and ghrelin levels.

Further investigations have also indicated a feedback loop between the pituitary-adrenal axis and ghrelin levels, as ghrelin administration showed an increase in ACTH and cortisol levels in healthy subjects (16, 17,19 ) and it induced a remarkable hyper-responsiveness in ACTH and cortisol levels in patients with active Cushing's syndrome (17). Wren et al. (19) suggested that ghrelin stimulates the HPA axis at the hypothalamic level, at least in part via corticotropin-releasing hormone and vasopressin.

We recently showed that circulating ghrelin levels are decreased in human obesity (20) and weight loss seems to increase circulating levels of ghrelin in human obesity (21). In contrast, plasma ghrelin concentrations are elevated in patients with anorexia nervosa and return to normal after partial weight gain (22). Ghrelin signals the central nervous system when an increase in metabolic efficiency is necessary (6). In our study, the decrease in BMI after curative surgery in patients with Cushing's syndrome showed a significantly inverse correlation with plasma ghrelin levels, indicating that plasma ghrelin might be involved in the pathogenesis of the obese phenotype associated with chronic hypercortisolism. BMI and plasma ghrelin levels were analyzed 3-24 months after surgery to make sure that the cortisol-induced fat mass had normalized. Hansen et al. (21) also found a correlation between an increase in ghrelin and a decrease in BMI in obese patients. These findings indicate that ghrelin is downregulated in a state of energy excess in obese subjects (21) or in chronic hypercortisolism. However, 
whether there are specific direct effects of ghrelin on adipose tissue or effects on the HPA axis is still unclear $(23,24)$. The decrease in plasma ghrelin after exogenous cortisol treatment in our study seems to suggest a feedback mechanism which mainly involves the peripheral part of the HPA axis.

Obesity and Cushing's syndrome are two pathophysiological states of hyperleptinemia and relative $\mathrm{GH}$ deficiency. Grottoli et al. (25) showed that a fastinginduced reduction in leptin and the GH response to fasting are blunted in both conditions. As recently described, insulin levels after fasting remained higher in patients with obesity and in chronic hypercortisolism, suggesting the possibility that hyperinsulinemia and variations in glucose levels or insulin sensitivity could play a role in the altered response of leptin and GH (25) and might also have an influence on ghrelin release (10). It remains to be investigated whether lower ghrelin levels in obese patients are - at least in part - responsible for their decreased GH secretion. In our study, we found a significant increase in serum IGF-I levels in healthy subjects following prednisolone administration. These changes showed a significant and strong correlation with the simultaneous decrease in plasma ghrelin levels and was observed after as few as 5 days. In contrast, in obese patients GH hyposecretion with corresponding lower IGF-I levels (25) and low plasma ghrelin concentrations (20) was found, probably due to long-term metabolic changes. Our findings in healthy subjects might reflect an effect of acute changes initiated by hypercortisolism and the resulting hyperinsulinemia. In addition, a negative feedback mechanism of GH/IGF-I on ghrelin secretion, described by Cappiello et al. (26), might have occurred.

Recently published data showed that steroids, such as sex hormones, modulate circulating plasma ghrelin concentration in humans: testosterone replacement therapy restores normal ghrelin levels in hypogonadal men (27) and obese women with polycystic ovary syndrome have even lower ghrelin levels when compared with obese subjects (28). In our study, we found an influence of another steroid, cortisol, on ghrelin concentrations in humans. These findings indicate that an interplay between steroid hormones of both the HPA as well as the hypothalamo-pituitary-gonadal axis might play a relevant role in the regulation of metabolism and body composition under conditions of health and disease.

In summary, ghrelin levels are low under the influence of corticosteroids and increase in their absence. Low ghrelin levels in Cushing's syndrome, a disease state presenting with increased fat mass and decreased muscle mass, therefore does not seem to involve ghrelin as part of the molecular pathophysiology behind these changes. In Cushing's syndrome, reduced ghrelin secretion could reflect a compensation mechanism in reaction to the metabolic consequences of chronic hypercortisolism. Apparently, ghrelin secretion also underlies a direct suppressing influence of circulating corticosteroid concentrations as shown by low plasma ghrelin in healthy volunteers following experimental administration of prednisolone.

\section{Acknowledgements}

The authors thank M Petrovitsch and P Exner for technical assistance.

\section{References}

1 Kojima M, Hosoda H, Date Y, Nakazato M, Matsuo H \& Kangawa $\mathrm{K}$. Ghrelin is a growth-hormone-releasing acylated peptide from stomach. Nature $1999 \mathbf{4 0 2} 656-660$.

2 Date Y, Kojima M, Hosoda H, Sawaguchi A, Mondal MS, Suganuma T, Matsukura S, Kangawa K \& Nakazato M. Ghrelin, a novel growth hormone-releasing acylated peptide, is synthesized in a distinct endocrine cell type in the gastrointestinal tracts of rats and humans. Endocrinology $20001414255-4261$.

3 Tschöp M, Flora DB, Mayer JP \& Heiman ML. Hypophysectomy presents ghrelin-induced adiposity and increases gastric ghrelin secretion in rats. Obesity Research $200210991-999$.

4 Nakazato M, Murakami N, Date Y, Kojima M, Matsuo H, Kangawa K \& Matsukura S. A role for ghrelin in the central regulation of feeding. Nature $2001 \mathbf{4 0 9} 194-198$.

5 Wren AM, Seal LJ, Cohen MA, Brynes AE, Frost GS, Murphy KG, Dhillo WS, Ghatei MA \& Bloom SR. Ghrelin enhances appetite and increases food intake in humans. Journal of Clinical Endocrinology and Metabolism $2001865992-5995$.

6 Tschöp M, Smiley DL \& Heiman ML. Ghrelin induces adiposity in rodents. Nature $2000 \mathbf{4 0 7} 908-913$.

7 Horvath TL, Diano S, Sotonyi P, Heiman M \& Tschöp M. Minireview: ghrelin and the regulation of energy balance - a hypothalamic perspective. Endocrinology $20011424163-4169$.

8 Cowley MA, Smith RG, Diano S, Tschöp M, Pronchuk N, Grove KL, Strasburger CJ, Bidlingmaier M, Esterman M, Heiman ML, Garcia-Segura LM, Nillni EA, Mendez P, Low MJ, Sotonyi P, Friedman JM, Liu H, Pinto S, Colmers WF, Cone RD \& Horvath TL. The distribution and mechanism of action of ghrelin in the CNS demonstrates a novel hypothalamic circuit regulating energy homeostasis. Neuron 200337 649-661.

9 McCowen KC, Maykel JA, Bistrian BR \& Ling PR. Circulating ghrelin concentrations are lowered by intravenous glucose or hyperinsulinemic euglycemic conditions in rodents. Journal of Endocrinology $2002 \mathbf{1 7 5}$ R7-R11.

10 Möhlig M, Spranger J, Otto B, Ristow M, Tschöp M \& Pfeiffer AF. Euglycemic hyperinsulinemia, but not lipid infusion, decreases circulating ghrelin levels in humans. Journal of Endocrinological Investigation 200225 RC36-RC38.

11 Saad MF, Bernaba B, Hwu CM, Jinagouda S, Fahmi S, Kogosov E \& Boyadjian R. Insulin regulates plasma ghrelin concentration. Journal of Clinical Endocrinology and Metabolism $2002 \quad 87$ 3997-4000.

12 Flanagan DE, Evans ML, Monsod TP, Rife F, Heptulla RA, Tamborlane WV \& Sherwin RS. The influence of insulin on circulating ghrelin. American Journal of Physiology. Endocrinology and Metabolism 2003284 E313-E316.

13 Schaller G, Schmidt A, Pleiner J, Woloszczuk W, Wolzt M \& Luger A. Plasma ghrelin concentrations are not regulated by glucose or insulin: a double-blind, placebo-controlled crossover clamp study. Diabetes $2003 \mathbf{5 2} 16-20$.

14 Caixas A, Bashore C, Nash W, Pi-Sunyer F \& Laferrere B. Insulin, unlike food intake, does not suppress ghrelin in human subjects. Journal of Clinical Endocrinology and Metabolism $2002 \quad 87$ $1902-1906$. 
15 English PJ, Ghatei MA, Malik IA, Bloom SR \& Wilding JP. Food fails to suppress ghrelin levels in obese humans. Journal of Clinical Endocrinology and Metabolism 200287 2984-2987.

16 Arvat E, Maccario M, Di Vito L, Broglio F, Benso A, Gottero C, Papotti M, Muccioli G, Dieguez C, Casanueva FF, Deghenghi R, Camanni F \& Ghigo E. Endocrine activities of ghrelin, a natural growth hormone secretagogue (GHS), in humans: comparison and interactions with hexarelin, a nonnatural peptidyl GHS, and GH-releasing hormone. Journal of Clinical Endocrinology and Metabolism 200186 1169-1174.

17 Leal-Cerro A, Torres E, Soto A, Dios E, Deghenghi R, Arvat E, Ghigo E, Dieguez C \& Casanueva FF. Ghrelin is no longer able to stimulate growth hormone secretion in patients with Cushing's syndrome but instead induces exaggerated corticotropin and cortisol responses. Neuroendocrinology 200276 390-396.

18 Gambineri A, Pagotto U, Tschöp M, Vicennati V, Manicardi E, Carcello A, Cacciari M, De Iasio R \& Pasquali R. Anti-androgen treatment increases circulating ghrelin levels in obese women with polycystic ovary syndrome. Journal of Endocrinological Investigation 200326 629-634.

19 Wren AM, Small CJ, Ward HL, Murphy KG, Dakin CL, Taheri S, Kennedy AR, Roberts GH, Morgan DG, Ghatei MA \& Bloom SR. The novel hypothalamic peptide ghrelin stimulates food intake and growth hormone secretion. Endocrinology $2000 \mathbf{1 4 1}$ 4325-4328.

20 Tschöp M, Weyer C, Tataranni AP, Denarayan V, Ravussin E \& Heiman ML. Circulating ghrelin levels are decreased in human obesity. Diabetes $200150707-709$.

21 Hansen TK, Dall R, Hosoda H, Kojima M, Kangawa K, Christiansen JS \& Jorgensen JO. Weight loss increases circulating levels of ghrelin in human obesity. Clinical Endocrinology $2002 \mathbf{5 6}$ 203-206.

22 Otto B, Cuntz U, Fruehauf E, Folwaczny C, Riepl RL, Lehnert P, Fichter M \& Tschop M. Weight gain decreases elevated plasma ghrelin concentrations of patients with anorexia nervosa. European Journal of Endocrinology 2001145 669-673.

23 Ott V, Fasshauer M, Dalski A, Meier B, Perwitz N, Klein HH, Tschop M \& Klein J. Direct peripheral effects of ghrelin include suppression of adiponectin expression. Hormone and Metabolic Research 200234 640-645.

24 Wren AM, Small CJ, Fribbens CV, Neary NM, Ward HI, Seal LJ, Ghatei MA \& Bloom SR. The hypothalamic mechanisms of the hypophysiotropic action of ghrelin. Neuroendocrinology $2002 \mathbf{7 6}$ 316-324.

25 Grottoli S, Gauna C, Tassone F, Aiaretti G, Corneli G, Wu Z, Strasburger CJ, Dieguez C, Casanueva FF, Ghigo E \& Maccario M. Both fasting-induced leptin reduction and $\mathrm{GH}$ increase are blunted in Cushing's syndrome and in simple obesity. Clinical Endocrinology 200358 220-228.

26 Cappiello V, Ronchi C, Morpurgo PS, Epaminonda P, Arosio M, Beck-Peccoz P \& Spada A. Circulating ghrelin levels in basal conditions and during glucose tolerance test in acromegalic patients. European Journal of Endocrinology 2002147 189-194.

27 Pagotto U, Gambineri A, Pelusi C, Genghini S, Cacciari M, Otto B, Castaneda T, Tschop M \& Pasquali R. Testosterone replacement therapy restores normal ghrelin in hypogonadal men. Journal of Clinical Endocrinology and Metabolism $2003 \mathbf{8 8}$ 4139-4143.

28 Pagotto U, Gambineri A, Vicennati V, Heiman ML, Tschöp M \& Pasquali R. Plasma ghrelin, obesity, and the polycystic ovary syndrome: correlation with insulin resistance and androgen levels. Journal of Clinical Endocrinology and Metabolism $2002 \quad 87$ $5625-5629$

Received 23 March 2004

Accepted 31 March 2004 